\title{
Super Agent Chatbot “3S" Sebagai Media Informasi Menggunakan Metoda Natural Language Processing(NLP)
}

\author{
Herwin $^{1)}$, Khusaeri Andesa ${ }^{2)}$ \\ ${ }^{1}$ Program Studi Manajemen InformatikaSTMIK Amik Riau, \\ Jl.Purwodadi Km.10 Panam Pekanbaru \\ email: herwin@sar.ac.id \\ ${ }^{2}$ Program Studi Manajemen InformatikaSTMIK Amik Riau, \\ Jl.Purwodadi Km.10 Panam Pekanbaru \\ email: khusaeri@sar.ac.id
}

\begin{abstract}
STMIK Amik Riau has a portal on the website http://www.sar.ac.id which functions as a medium for disseminating information to academicians and stakeholders. The average number of visitors per day in the last 3 months is 150 visits, but there is an increase during student admissions in each academic year. This indicates an increase in public interest to find out information about STMIK Amik Riau. Unfortunately, until now the utilization of the web site portal is still one-way, from STMIK Amik Riau to stakeholders and the community, it has not happened otherwise. Problems arise when there is a misunderstanding about discounting tuition fees, the number of credits for each study program and special information not contained in the portal website To overcome these problems, we need a system that interacts between STMIK Amik Riau and the community using chatbots. This study aims to create chatbots that are able to communicate with website visitors. Chatbot that has been created is named STMIK Amik Riau Intelligence Virtual Information abbreviated as SILVI. Chatbot is based on Question Answering Systems (QAS), working with similarity algorithms between two texts. This research resulted in an application that is ready to use, named SILVI, able to communicate with website visitors. Chatbot optimizes communication as if it is not aware, still considers the other person to be the right employee in the main tasks and functions.
\end{abstract}

Keywords: $3 S$, chatbot, similarity, stake holder

\begin{abstract}
Abstrak
STMIK Amik Riau memiliki portal pada website http://www.sar.ac.id difungsikan sebagai media penyebaran informasi bagi sivitas akademika dan stakeholder. Rerata pengunjung setiap hari dalam 3 bulan terakhir adalah 150 kunjungan, namun terjadi peningkatan pada saat penerimaan mahasiswa di setiap tahun akademik. Hal ini mengindikasikan terjadinya peningkatan minat masyarakat untuk mengetahui informasi STMIK Amik Riau. Sayangnya, sampai saat ini pemanfaatan portal web site masih satu arah, dari STMIK Amik Riau ke stakeholder dan masyarakat, tidak terjadi sebaliknya.Permasalahan muncul ketika terjadi salah pemahaman tentang discount biaya kuliah, jumlah SKS tiap program studi dan informasi khusu yang belum termuat di portal website Untuk mengatasi permasalahan tersebut, maka diperlukan sebuah sistem yang berinteraksi antara STMIK Amik Riau dengan masyarakat dengan menggunakan chatbot. Penelitian ini bertujuan membuat chatbot yang mampu berkomunikasi dengan pengunjung website. Chatbot yang telah dibuat diberi nama STMIK Amik Riau Intelligence Virtual Information disingkat SILVI. Chatbot dibuat berdasarkan Question Answering Systems (QAS), bekerja dengan algoritma kemiripan antara dua teks. Penelitian ini menghasilkan aplikasi yang siap digunakan, diberi nama SILVI, mampu
\end{abstract}


Hal : $53-64$

berkomunikasi dengan pengunjung website. Chatbot mengoptimalkan komunikasi seolah tidak menyadari, tetap menganggap lawan bicara adalah pegawai yang tepat dalam tugas pokok dan fungsi.

Kata Kunci : Senyum sapa salam, chatbot, similarity, stake holder

\section{PENDAHULUAN}

Pada saat ini media promosi berbasis web merupakan trend terbaru, sementara Perguruan Tinggi sampai saat ini belum memanfaatkan potensi tersebut secara optimal. Pada saat ini media untuk memperoleh informasi akademik dimuat pada portal web STMIK Amik Riau. Sebagian informasi yang ada diportal tersebut belum semuanya memenuhi kebutuhan dari masyarakat ataupun calon mahasiswa.

Setiap tahun sebagian besar mahasiswa yang masuk di STMIK Amik Riau memperoleh informasi dari teman, sanak saudara yang pernah kuliah disini. Hal ini terbukti pada saat wawancara penerimaan mahasiswa baru bahwa hanya 30\% saja calon mahasiswa yang memperoleh informasi dari website.

Permasalahan yang dialami STMIK Amik Riau adalah ketika calon mahasiswa menanyakan jumlah SKS setiap program studi, sistem pembelajaran dan atau kondisi tertentu yang belum tersedia di portal website. Layanan informasi terbaik kepada masyarakat dan stakeholder secara online dan realtime menggunakan Bahasa Indonesia adalah sangat diperlukan sekali, tanpa melibatkan civitas akademik maupun tenaga kependidikan. Pemecahan yang diajukan untuk menyelesaikan masalah yang dialami STMIK Amik Riau adalah penerapan Super Agent chatbot dengan menggunakan Natural Language Processing (NLP), pada area Question Answering Systems.

Natural Language Processing, adalah cabang ilmu komputer dan linguistik yang mengkaji interaksi antara komputer dengan bahasa alami manusia. Pemilihan metode NLP karena merupakan kecerdasan buatan dan bidang kajiannya bersinggungan dengan linguistik komputasional. Mudah melakukan interaksi luwes dan powerfull dan kajian NLP antara lain mencakup segmentasi tuturan (speech segmentation), segmentasi teks (text segmentation), penandaan kelas kata (part-of-speech tagging), serta pengawataksaan makna (word sense disambiguation).

\section{TINJAUAN PUSTAKA}

\subsection{Aplikasi Chatbot " $3 S$ "}

Chatbot merupakan sebuah program komputer yang dapat menjalankan intelligent conversation dengan pengguna melalui media suara ataup teks, seringkali dilakukan dengan percakapan yang singkat (Tillotson, 2012). Chatbot bekerja dengan mengartikan pesan yang diberikan oleh pengguna, kemudian memproses maksud dari pesan tersebut, selanjutnya menentukan dan mengeksekusi apa yang perlu chatbot lakukan berdasarkan perintah dari pengguna, dan terakhir menyampaikan hasil dari eksekusi kepada pengguna (Shawar, 2007).

\subsection{Informasi}

Menurut (Fajri, 2014) informasi dapat diartikan suatu data yang telah diproses dan diubah menjadi konteks yang berarti sehingga memiliki makna dan nilai bagi penerimanya dan biasa digunakan untuk pengambilan keputusan. 
Hal : $53-64$

\subsection{Question Answering Systems}

Menurut Monz (2003) QA system merupakan sebuah sistem yang mengijinkan user menyatakan kebutuhan informasinya dalam bentuk yang lebih spesifik dan alami, yaitu dalam bentuk natural language question, dan tidak mengembalikan daftar dokumen yang harus disaring oleh user untuk menentukan apakah dokumen-dokumen tersebut mengandung jawaban atas pertanyaan, tetapi mengembalikan kutipan teks singkat atau bahkan frase sebagai jawaban.

\subsection{Cosine Similarity (Indonesia)}

Cosine Similarity dapat diimplementasikan untuk menghitung nilai kemiripan antar kalimat dan menjadi salah satu teknik untuk mengukur kemiripan teks yang popular. Contoh penggunaan Cosine Similarity dalam menguji kemiripan dua buah kalimat adalah sebagai berikut:

Diberikan dua buah kalimat yaitu kalimat A dan B, yaitu:

A : Julie loves me more than Linda loves me

B : Jane likes me more than Julie loves me

Uji kemiripan teks dilakukan dengan rumus:

$\frac{\sum_{n=1}^{j}(n A x n B)}{\sqrt{\sum_{n=1}^{j}(n \boldsymbol{A})^{2}} x \sqrt{\sum_{n=1}^{j}(n \boldsymbol{B})^{2}}}$

Dengan: $\mathrm{j}=|\mathrm{A} \cap \mathrm{B}|$ Kemiripan =

Rumus Cosine Similarity

$\mathrm{nA}=$ jumlah kemunculan kata indeks ke-n dari daftar kata pada kalimat A.

$\mathrm{nB}=$ jumlah kemunculan kata indeks ke-n dari daftar kata pada kalimat $\mathrm{B}$

\section{METODE PENELITIAN}

\subsection{Tahapan Tahap Penelitian}
a. Mengidentifikasi Masalah
b. Membuat Hipotesa
c. Studi Literature
d. Mengidentifikasi dan Menamai Variabel
e. Membuat Definisi Operasional
f. Memanipulasi dan Mengontrol Variabel
g. Menyusun Desain Penelitian
h. Mengidentifikasi dan Menyusun Alat Observasi dan Pengukuran
i. Membuat Kuesioner dan Jadwal Interview
j. Melakukan Analisa Statistik
k. Menggunakan Komputer untuk Analisa Data
1. Menulis Laporan Hasil Penelitian 
Hal : $53-64$

\subsection{Teknik Analisis}

Analisis Sebelum di Lapangan, analisis dilakukan terhadap data hasil studi pendahuluan, atau data sekunder yang akan digunakan untuk menentukan fokus penelitian. Sebelum masuk lapangan, peneliti mempersiapkan beberapa pertanyaan yang berkaitan dengan fokus penelitian yaitu melalui observasi, dokumentasi, dan wawancara yang akan diberikan secara langsung sivitas dan tenaga kependidikan STMIK Amik Riau Analisis selama di lapangan, mengemukakan bahwa aktivitas dalam analisis data kualitatif dilakukan secara interaktif dan berlangsung secara terus menerus sampai tuntas, sehingga datanya yang diperoleh sudah cukup.

\subsection{Teknik Pengumpulan Data}

Pengumpulan data ini dilakukan untuk memperoleh hasil yang optimal dalam penyelesaian masalah. Adapun teknik yang digunakan dalam penelitian ini adalah :

1. Observasi, melakukan amatan terhadap Pembimbing Akademis dalam melayani mahasiswa, orang tua mahasiswa, tamu dari masyarakat luas, tamu dari dinas pendidikan, maupun pengawas, langkah yang dilakukan tenaga pendidik maupun tenaga kependidikan dalam memberikan informasi secara langsung maupun melalui jaringan media sosial, suara dan layanan SMS.

2. Wawancara, melakukan wawancara dengan tenaga pendidik, pembimbing akademik, prodi, tenaga kependidikan, masyarakat luas, serta stakeholder tentang upaya kampus dalam memberikan informasi serta media yang digunakan. Berikut pertanyaan yang di ajukan dalam bentuk kusioner terhadap 10 orang user:

Tabel 1: Pertanyaan kusioner

\begin{tabular}{|l|l|l|l|l|l|l|}
\hline \multirow{2}{*}{ No } & \multicolumn{1}{|c|}{ Pertanyaan } & \multicolumn{3}{c|}{ Penilaian } \\
\cline { 3 - 7 } & & TS & KS & CS & S & SS \\
\hline 1. & $\begin{array}{l}\text { Saat membuka aplikasi, apakah pengguna } \\
\text { mengerti apa yang harus dilakukan }\end{array}$ & & & & & \\
\hline 2. & $\begin{array}{l}\text { Berinteraksi dengan chabot yang menggunakan } \\
\text { budaya "3S" }\end{array}$ & & & & & \\
\hline 3 & $\begin{array}{l}\text { Setelah memulai komunikasi dengan chatbot, } \\
\text { apakah user dapat berinteraksi }\end{array}$ & & & & & \\
\hline 4 & $\begin{array}{l}\text { Informasi /jawaban yang diberikan aplikasi ini } \\
\text { apa sudah sesuai dengan yang } \\
\text { ditanyakan/dimaksud pengunjung }\end{array}$ & & & & & \\
\hline 5 & $\begin{array}{l}\text { Aplikasi dapat menjadi salah satu referensi } \\
\text { lengkap yang juga menarik tentang informasi }\end{array}$ & & & & & \\
\hline
\end{tabular}


Hal : $53-64$

\begin{tabular}{|l|l|l|l|l|l|l|} 
& STMIK Amik Riau & & & & & \\
\hline 6. & Perlu pembaruan untuk menyempurnakan sistem & & & & & \\
\hline 7. & $\begin{array}{l}\text { User mengasosiasikan chatbot SILVI dengan } \\
\text { budaya "3S" sebagai seseorang yang ramah dan } \\
\text { menyenangkan. }\end{array}$ & & & & & \\
\hline 8. & $\begin{array}{l}\text { User memahami sepenuhnya bahwa teman } \\
\text { bicara adalah komputer bukan manusia. }\end{array}$ & & & & & \\
\hline
\end{tabular}

Skala jawaban: 1. TS = Tidak Setuju 2. KS = Kurang Setuju 3. CS = Cukup Setuju 4. $\mathrm{S}=$ Setuju 5. SS = Sangat Setuju

3. Studi pustaka, menemukan artikel ilmiah yang relevan untuk mendapat riset terdahulu tentang penggunaan chatbot, Natural Language Processing, Question Answer System, algoritma string matching, perolehan kemiripan kalimat, dan penggabungan chatbot dan algoritma string matching, penerapan chatbot dalam memberikan informasi.

Data yang diperoleh dijadikan untuk melakukan pengujian dan pembuktian penerapan algoritma string matching dengan berbasis NLP

\section{HASIL DAN PEMBAHASAN}

\subsection{Metoda Similirity}

Setiap pengunjung yang melakukan komunikasi dengan Super Agent chatbot "3S" secara otomotis sistem memberikan sebuah ID unik yang akan digunakan oleh sistem sebagai pembeda antara satu pengunjung dengan pengunjung yang lain. Pengunjung yang dapat terkoneksi pada waktu bersamaan merujuk pada default web server. Pengunjung melakukan interaksi dengan chatbot melalui media yang telah disediakan pada sisi kanan bawah layar komputer. Kalimat yang di ketik pada form oleh pengunjung, chatbot melakukan seleksi terhadap data training yang telah disediakan melalui algoritma similarity. Proses pencarian dan pemilihan tersebut, didasarkan pada kesamaan kalimat yang diketik pengunjung dengan kalimat yang tersedia pada database. Kesamaan tersebut harus memenuhi $70 \%$, bila terpenuhi Aplikasi chatbot " 3 S" akan mengambil response yang sudah tersedia untuk dikirimkan ke pengunjung sebagai jawaban. Bila kesamaan kalimat $70 \%$ tidak terpenuhi, sistem akan memberikan jawaban default yang sudah disediakan berupa "Maaf saya masih kurang paham, mohon diulangi". Pertanyaan yang diajukan pengunjung bila tidak tersedia jawaban yang memenuhi $70 \%$ kesamaan huruf, langsung di rekam. Administrator memberikan jawaban yang sesuai. Proses tersebut akan berlangsung untuk setiap ada respon kalimat dari pengunjung. 
Hal : $53-64$

Tabel 2: hasil penilaian pengunjung

\begin{tabular}{|l|l|l|}
\hline No & Nilai & Keterangan \\
\hline 1. & $0 \%-20 \%$ & Tidak Setuju \\
\hline 2. & $21 \%-40 \%$ & Kurang Setuju \\
\hline 3. & $41 \%-60 \%$ & Cukup Setuju \\
\hline 4. & $61 \%-80 \%$ & Setuju \\
\hline 5. & $81 \%-100 \%$ & Sangat Setuju \\
\hline
\end{tabular}

$$
P=\frac{Q \times 200}{A+B}
$$

Keterangan:

$\mathrm{P}=$ Jumlah karakter sama antara pertanyaan yang diajukan pengunjung dengan pertanyaan yang tersedia pada database

$\mathrm{A}=$ Jumlah karakter yang telah diketik oleh pengunjung

$\mathrm{B}=$ Jumlah karakter yang dimungkinkan pertanyaan yang sama pada database

Jika perbandingan antara pertanyaan yang di input oleh user dengan pertanyaan yang ada di dalam database lebih besar atau sama dengan 70\% maka tampilkan jawaban yang ada didalam database. Jika kurang dari $70 \%$ pertanyaan yang di input oleh user akan disimpan didalam database kemudian kepada user akan diberikan jawaban default. Pengunjung mengetikkan kalimat A, berbunyi "Biaya Kuliah", kemungkinan kalimat B yang hampir sama pada database adalah "Biaya Masuk", karakter yang sama dari kalimat A dan kalimat $\mathrm{B}$ adalah $\mathrm{P}$ sebanyak 7, maka dihasilkan kemiripan antara kalimat $\mathrm{A}$ yang di ketik oleh pengunjung dengan kalimat B yang tersedia pada database sebesar $60 \%$.

Contoh 1: Tingkat kemiripan kalimat dibawah 70\%

Hasil akhir, Aplikasi Chatbot "3S" memberikan jawaban default untuk setiap kalimat yang tidak memenuhi kemiripan $70 \%$ sesuai dengan yang termuat di dalam database. Skenario adalah :

Kalimat dari pengunjung adalah A= "Biaya Kuliah"

Kalimat tersedia pada database adalah B= "Biaya Masuk" 
Hal : $53-64$

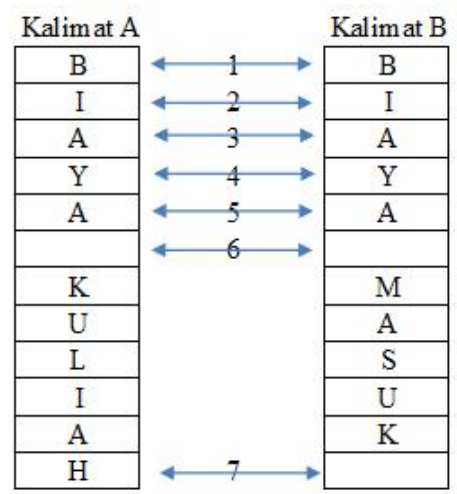

Gambar 2.contoh intruksi

Jumlah karakter sama $=7$

Karakter pada kalimat A + Karakter pada kalimat B $=23$

Maka:

$$
\begin{aligned}
& P=\frac{7 \times 200}{23} \\
& P=60 \%
\end{aligned}
$$

Jawaban yang diberikan SILVI kepada user adalah "Saya belum mengerti maksud dan tujuan anda kemana"

Contoh 2: Kemiripan kalimat lebih dari 70\%

Hasil akhir, Aplikasi Chatbot "3S" memberikan jawaban sesuai dengan yang termuat di dalam database. Skenario adalah :

Kalimat dari pengunjung adalah A="Bagaimana sistem perkuliahan";

Kalimat tersedia pada database adalah $\mathrm{B}=$ "Bagaimana sistem belajarnya";

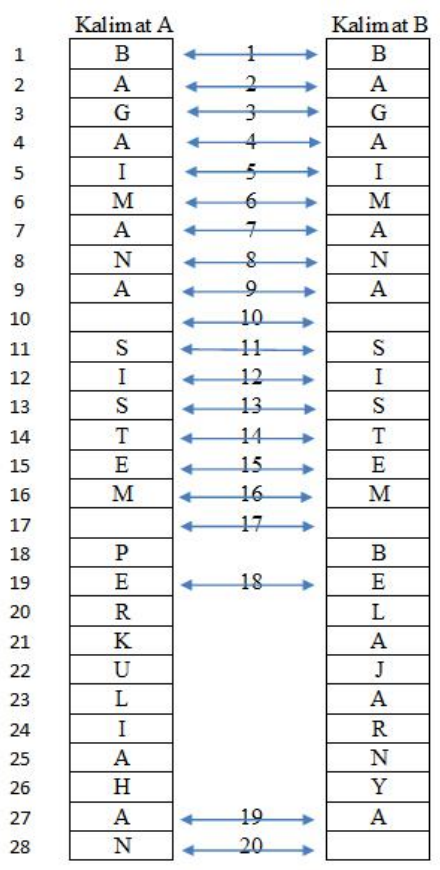


Hal : $53-64$

Gambar 3. Pengujian untuk 3 kata

\begin{tabular}{l}
$20 \times 200$ \\
- \hdashline $27+27$
\end{tabular}$=\begin{gathered}4000 \\
------=72 \%\end{gathered}$

Jumlah karakter sama $=20$

Karakter pada kalimat A + Karakter pada kalimat $\mathrm{B}=55$

Maka:

$$
\begin{gathered}
P=\frac{20 \times 200}{28+27} \\
P=72 \%
\end{gathered}
$$

Jawaban yang diberikan SILVI kepada user adalah "Semester 1 dan 2, sistem paket, selanjutnya menggunakan sistem kredit semester (SKS)"

\subsection{Implementasi}

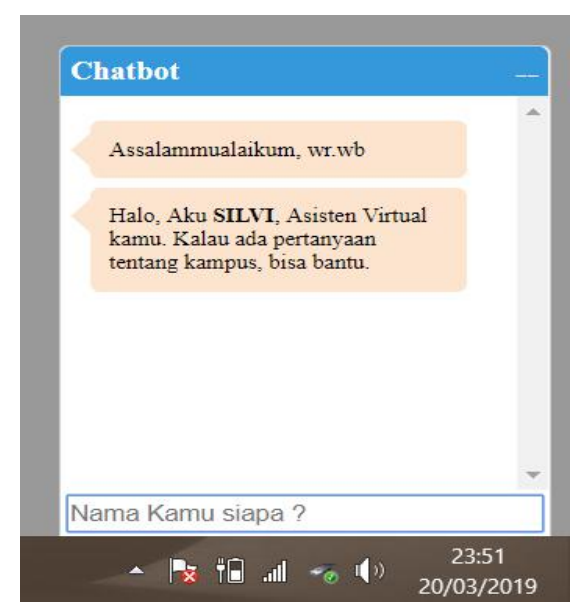

Gambar 4. Layar dialog chat bot respon

Pada gambar 4 adalah tampilan chatbot yaitu kolom chabot yang berfungsi untuk menanyakan pertanyaan tentang informasi yang ada di kampus.

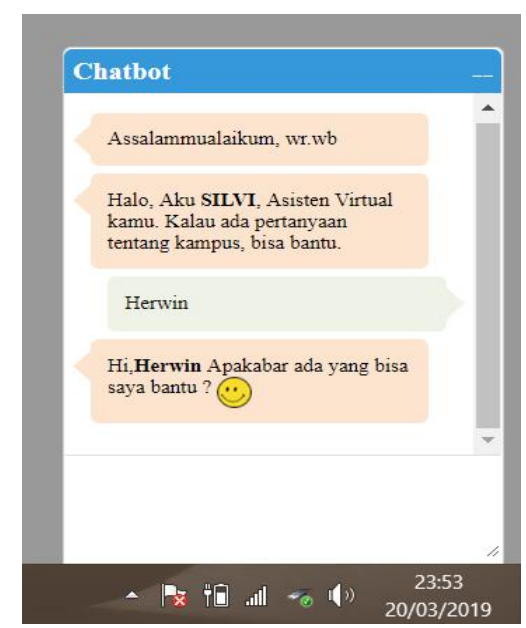

Gambar 5. Layar dialog sistem merespon nama user 
Hal : $53-64$

Tampilan chatbot yang menampilkan jawaban dari pertanyaan sebelumnya. Halaman jawaban chatbot ditunjukkan gambar 5 .

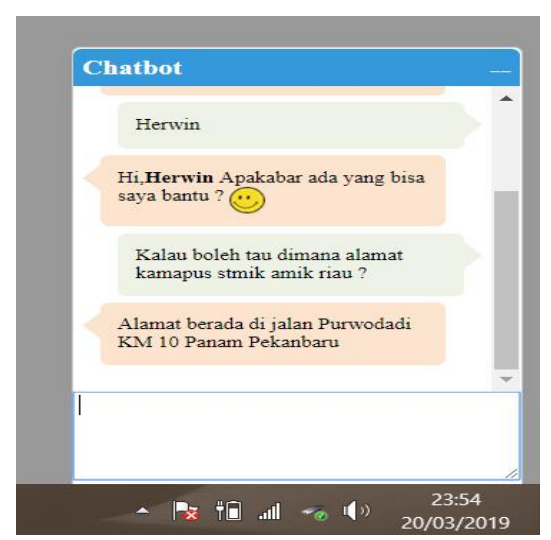

Gambar 6. dialog chatbot respon alamat kampus

Pada gambar 6 merupakan tampilan chatbot yang menampilkan jawaban dari pertanyaan alamat kampus

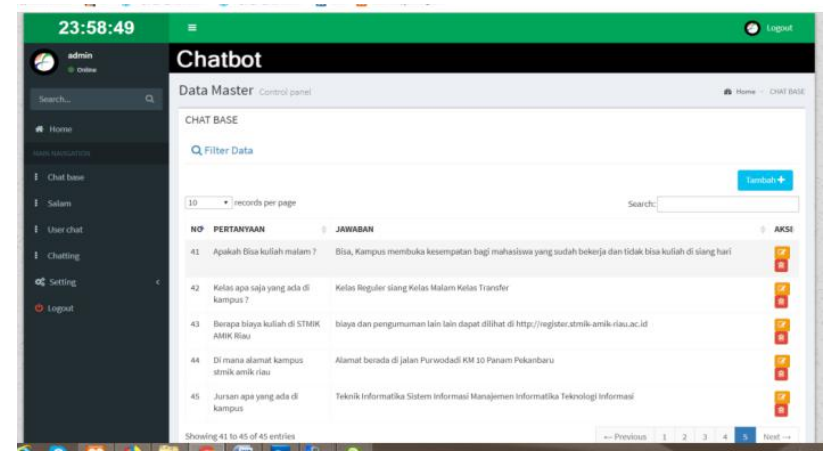

Gambar 7. Layar dialog chatbase

Pada gambar 7 memperlihatkan halaman admin untuk chatbase, Halaman ini berisi pertanyaan dan jawaban yang sudah disiapkan. Pertanyaan dan jawaban bisa ditambah, dihapus dan di update.

\subsection{Hasil Pengujian}

1. Bagian Login

\begin{tabular}{|l|l|l|l|}
\hline Data Masukan & Diharapkan & Pengamatan & Kesimpulan \\
\hline User Name & $\begin{array}{l}\text { Jika username } \\
\text { terdaftar maka } \\
\text { menghasilkan nama } \\
\text { real }\end{array}$ & $\begin{array}{l}\text { pada saat username } \\
\text { selesai di inputkan } \\
\text { (lost focus), nama } \\
\text { user langsung } \\
\text { tampil }\end{array}$ & diterima \\
\hline & Jika username & Pada saat username & diterima \\
\hline
\end{tabular}


Hal : $53-64$

\begin{tabular}{|l|l|l|l|}
\hline & $\begin{array}{l}\text { tidak terdaftar } \\
\text { maka keluar pesan } \\
\text { user tidak sesuai }\end{array}$ & $\begin{array}{l}\text { selesai di inputkan, } \\
\text { langsung muncul } \\
\text { pesan 'login user } \\
\text { gagal' }\end{array}$ & \\
\hline $\begin{array}{l}\text { Tekan tombol } \\
\text { Submit }\end{array}$ & $\begin{array}{l}\text { Jika user name dan } \\
\text { password sesuai } \\
\text { maka aktif halaman } \\
\text { administrator }\end{array}$ & $\begin{array}{l}\text { Tampil halaman } \\
\text { administrator }\end{array}$ & diterima \\
\hline & $\begin{array}{l}\text { Jika user name dan } \\
\text { password tidak } \\
\text { sesuai }\end{array}$ & $\begin{array}{l}\text { Tampil halaman } \\
\text { login gagal }\end{array}$ & diterima \\
\hline
\end{tabular}

2. Bagian Chat base

\begin{tabular}{|c|c|c|c|}
\hline Data Masukan & Diharapkan & Pengamatan & Kesimpulan \\
\hline \multirow[t]{2}{*}{ Klik tambah } & $\begin{array}{l}\text { Sistem } \\
\text { menampilkan form } \\
\text { pertanyaan dan } \\
\text { jawaban }\end{array}$ & $\begin{array}{l}\text { Sistem } \\
\text { menampilkan form } \\
\text { yang berisi item } \\
\text { pertanyaan dan } \\
\text { jawaban }\end{array}$ & diterima \\
\hline & $\begin{array}{l}\text { Mengetik } \\
\text { pertanyaan dan } \\
\text { jawaban }\end{array}$ & & diterima \\
\hline Klik Simpan & $\begin{array}{l}\text { Sistem menyimpan } \\
\text { isi pertanyaan dan } \\
\text { isi jawaban ke } \\
\text { database }\end{array}$ & & diterima \\
\hline Klik batal & $\begin{array}{l}\text { Sistem kembali ke } \\
\text { halaman } \\
\text { administrator }\end{array}$ & $\begin{array}{l}\text { Sistem kembali } \\
\text { menampilkan } \\
\text { halaman utama }\end{array}$ & diterima \\
\hline
\end{tabular}

3. Bagian Salam

\begin{tabular}{|l|l|l|l|}
\hline Data Masukan & Diharapkan & Pengamatan & Kesimpulan \\
\hline $\begin{array}{l}\text { chat salam } \\
\text { pembuka }\end{array}$ & $\begin{array}{l}\text { tampil chat salam } \\
\text { pembuka pada saat } \\
\text { user pertama } \\
\text { membuka halaman } \\
\text { web }\end{array}$ & $\begin{array}{l}\text { chat salam } \\
\text { pembuka, tampil. }\end{array}$ & diterima \\
& & \\
\hline
\end{tabular}


Hal : $53-64$

\section{Bagian User Chat}

\begin{tabular}{|l|l|l|l|}
\hline Data Masukan & Diharapkan & Pengamatan & Kesimpulan \\
\hline $\begin{array}{l}\text { user input nama } \\
\text { pada halaman chat }\end{array}$ & $\begin{array}{l}\text { sistem } \\
\text { menampilkan nama } \\
\text { user serta informasi } \\
\text { tambahan }\end{array}$ & $\begin{array}{l}\text { nama user dan } \\
\text { informasi tambahan } \\
\text { tampil dihalaman } \\
\text { chat }\end{array}$ & diterima \\
\hline
\end{tabular}

\section{Bagian Chatting}

\begin{tabular}{|l|l|l|l|}
\hline Data Masukan & Diharapkan & Pengamatan & Kesimpulan \\
\hline $\begin{array}{l}\text { user chat dengan } \\
\text { SILVI }\end{array}$ & $\begin{array}{l}\text { Sistem menjawab } \\
\text { dengan jawaban } \\
\text { normal, jika } \\
\text { pertanyaan } \\
\text { memiliki kemiripan } \\
\text { kata }>70 \%\end{array}$ & $\begin{array}{l}\text { Sistem menjawab } \\
\text { jika pertanyaan } \\
\text { memiliki kemiripan } \\
\text { kata }>70 \% \text { pada } \\
\text { chat base }\end{array}$ & diterima \\
\hline & $\begin{array}{l}\text { Jika pertanyaan } \\
\text { memiliki kemiripan } \\
\text { kata }<70 \%\end{array}$ & $\begin{array}{l}\text { saya belum } \\
\text { mengerti maksud } \\
\text { dan tujuan anda } \\
\text { kemana" }\end{array}$ & diterima \\
\hline
\end{tabular}

\section{Setting}

\begin{tabular}{|l|l|l|l|}
\hline Data Masukan & Diharapkan & Pengamatan & Kesimpulan \\
\hline $\begin{array}{l}\text { ubah password } \\
\text { admin }\end{array}$ & $\begin{array}{l}\text { pasword dapat } \\
\text { diubah, apabila } \\
\text { admin klik tombol } \\
\text { ubah }\end{array}$ & $\begin{array}{l}\text { password dapat } \\
\text { diubah }\end{array}$ & diterima \\
\hline
\end{tabular}

\section{SIMPULAN}

Penelitian ini telah selesai dilaksanakan, satu diantara luaran adalah tersedianya Super Agent chatbot " $3 \mathrm{~S}$ " siap digunakan. Kesimpulan yang diperoleh adalah bahwa chatbot bekerja berdasarkan data training terhadap 10 pertanyaan dan data training jawaban sebagai data rujukan setiap kalimat dari pengunjung, Chatbot tidak bisa memberikan dan menampilkan ekspresi emosional, sekalipun user berupaya memberikan kalimat emosional, Chatbot tidak bisa menghubungkan diri dengan kondisi STMIK Amik Riau yang ada saat ini, database harus selalui diperbaharui untuk dapat memberikan informasi terbaru kepada pengunjung melalui chatbot,chatbot sebaiknya di tempatkan pada server yang memiliki kemampuan memproses mumpuni Dari kesimpulan itu ada beberapa saran perbaikan untuk penelitian selanjutnya antara lain. Aplikasi dirancang untuk mampu mengukur tingkat emosional pengunjung melalui pembobotan terhadap kata yang digunakan.Aplikasi 
dirancang untuk terhubung dengan operator, untuk setiap pertanyaan yang tidak dapat di selesaikan oleh chatbot. Chatbot perlu di training untuk terhubung dengan kondisi STMIK Amik Riau yang ada saat ini.

\section{UCAPAN TERIMAKASIH}

Ucapan terima kasih kepada lembaga penelitian uniks yang telah memberikan kesempatan untuk mempublikasikan penelitian saya ini.

\section{DAFTAR PUSTAKA}

Bayu Setiaji, (2013). Membangun Chatbot Berbasis AIML dengan Arsitektur Pengetahuan Moduler. Seminar nasional Teknologi Informasi dan Multimedia, STMIK AMIKOM Yokyakarta,19 Januari 2013.

Ahmad Alim Akhsan dan Faizah (2017). Analisis Dan Perancangan Interaksi Chatbot Reminder Dengan User Centered Design. Jurnal Sistem Informasi, 2(13).

Suryani, D, dan Amalia,EL, ( 2017). Chatbot Objek Wisata Jawa Timur Berbasis AIML, Jurnal SMARTICS,3( 2).

Maskur ,(2016). Chatbot Pusat Informasi Mahasiswa Menggunakan AIML Sebagai Virtual Assistant Berbasis Web, Jurnal KINETIK.

Elisabet Nila S. C. P, Irawan Afrianto (2015). Rancang Bangun Aplikasi Chatbot Informasi Objek Wisata Kota Bandung dengan Pendekatan Natural Language Processing. Jurnal Ilmiah Komputer dan Informatika (KOMPUTA), 4(1).

Stefanus Ardhito, dkk, (2018). Implementing Indonesian Language Chatbot For Ecommerce Site Using Artificial Intelligence Markup Language (AIML), Seminar Nasional Pakar ke 1 Tahun 2018,Buku 1

Tillotson, K. D., (2012).Implementation, Analysis, and Evaluation of A Humanized Information Retrieval ChatBot," Tesis, The Faculty of The Computer Science Department, Southern Un-iversity and A\&M College, Johor.

Shawar, B. A. and Atwell, E.(2007). Chatbot: are they really useful?, LDV-Forum 2007, 22( 1)

Allen, D.(2015).Getting things done: the art of str-ess-free productivity, New York: Penguin Books.

Gunawan, Lovina,Gita. (2006). Question Answering System dan penerapannya pada alkitab. Jurusan Teknik Informatika Sekolah tinggi Teknik Surabaya.

Tata Sutabri. 2012.Analisis Sistem Informasi.Andi. Yogyakarta 